\title{
DIÁLOGOS ENTRE HISTÓRIA DA ARTE \& NATUREZA
}

\author{
Autora: Amanda Delgado Ribeiro de Souza, UFPEL \\ dadsdelgado@hotmail.com \\ Orientadora: Caroline Leal Bonilha, UFPEL \\ bonilhacaroline@gmail.com
}

\section{RESUMO}

O trabalho tem por objetivo anunciar e refletir a respeito da relação do grupo de estudos "História e Teoria das Imagens: Diálogos entre Arte e Natureza", constituído por alunos da licenciatura e bacharelado de Artes Visuais da Universidade Federal de Pelotas, com a História da Arte. Relata os desenvolvimentos do grupo, que com o objetivo de compreender as relações entre indivíduo, arte e natureza, e refletir questões ambientais, inicia estudos desde as alterações na pintura de gênero, para o surgimento da pintura de paisagem na arte holandesa, refletindo também a preocupação de artistas do século XIX, como Felix Taunay, até as reflexões a respeito da importância da temática da $32^{\mathrm{a}}$ Bienal de São Paulo para os estudos do grupo. Com o intuito de aprofundar e esclarecer a compreensão do transito dinâmico do grupo na utilização da História da Arte é feita uma metáfora com a produção artística do pintor Paulo Pasta.

Palavras-chave: paisagem; história da arte; indivíduo; natureza; dinamismo.

\section{INTRODUÇÃO}

Este trabalho tem por objetivo apresentar discussões advindas do campo da História da Arte presentes no projeto de ensino "História e Teoria das Imagens: Diálogos entre Arte e Natureza" constituído por alunos da licenciatura e bacharelado de Artes Visuais da Universidade Federal de Pelotas. As ações do grupo iniciadas em 2016 contaram com forte presença de estudos relativos à história da pintura de paisagem. A fluidez dinâmica do grupo o aproxima da Arte Contemporânea, trazendo da estética um olhar diferenciado às obras estudadas. Sua projeção para ações e proposições práticas enriquecem as poéticas coletivas e individuais dos artistas e educadores em formação. 


\section{ANTECEDENTES}

A problematização das relações humanas com a natureza se faz importante na compreensão de sua representação na Arte Contemporânea, partindo de um viés histórico, que se deu inicialmente através das paisagens holandesas, conforme as imagens abaixo, Figura 1 e 2, produzidas no século XVII, decorrentes do processo de ocupação holandesa em território brasileiro. As imagens são de quadros dos artistas holandeses Frans Post (1612-1680) e Jacob Ruisdael (1628 - 1682), e nos interessaram por considerarmos abrupta a transformação da pintura holandesa que passa de cunho religioso, cuja figura humana era de maior destaque, para uma imagem a qual a paisagem ocuparia $2 / 3$ da área da tela, por tal razão o grupo se inclina para a discussão das alterações na pintura produzida em território holandês. Os estudos a respeito das paisagens holandesas que retratavam seu próprio território ocorreram através de duas formas, o levantamento de imagens devido ao inicial interesse do grupo, confrontado com leituras de teóricos que haviam refletido sobre tais transformações. As pinturas estudadas datam de períodos anteriores ao século XII até meados do século XVIII da região denominada Países Baixos. Foi a partir do século XVI que delimitamos os estudos e questionamentos, sempre mantendo o foco de que se objetivava uma aproximação das práticas artísticas contemporâneas desde 1960, considerando meio ambiente, arte e educação.

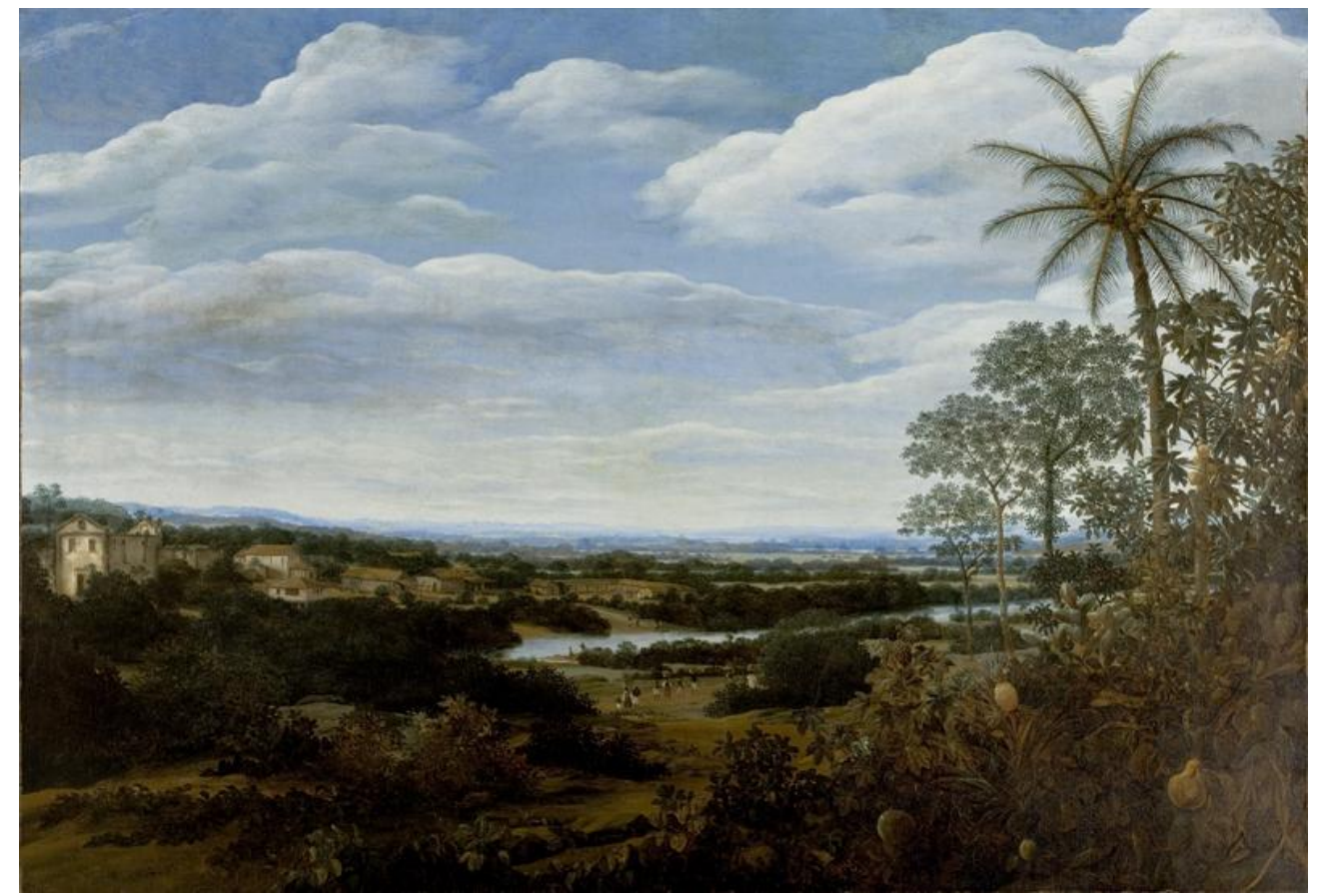

Figura 1. Paisagem com Jibóia (1660), Frans Post. Fonte: Acervo MASP, São Paulo, Brazil. Disnponível em: https://goo.gl/a0p2hq. 


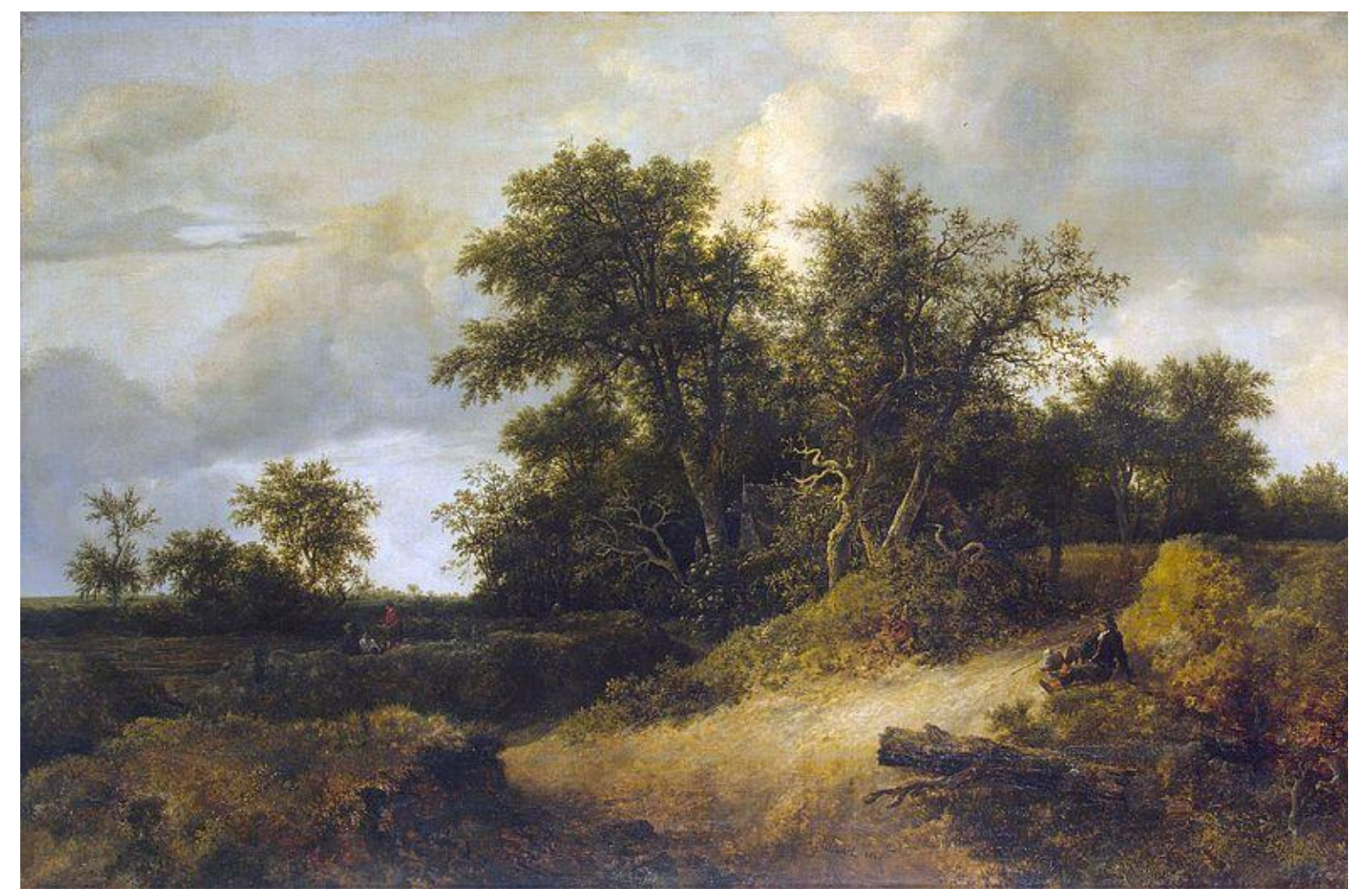

Figura 2. Paisagem das dunas (1646), Jacob Ruisdael. Fonte: acervo do Museu Hermitage, São Petesburgo, Rússia.

\section{DESENVOLVIMENTO}

Os estudos possibilitaram ampla compreensão sobre o gênero paisagem em variados territórios ocidentais, a respeito da pintura holandesa, por exemplo, a percepção da gradação até o surgimento da pintura de paisagem. Embora Kern (2011) atribua mudanças nas pinturas Holandesas à dessacralização da natureza e transgressão de concepções religiosas, muitos foram os artistas nascidos entre os séculos XV e XVI, cujas temáticas religiosas contaram com gradativos aumentos das proporções da paisagem em comparação às figuras humanas. A exemplo de Jan Wellens de Cock (1480-1527) e Jan Van Amstel (1500-1542) através do aparecimento de janelas, ou construções mais abertas. O que levou ao estudo de cada um dos artistas levantados, para melhor esclarecer como se deu o processo de transição. No entanto, o maior interesse do grupo não era a compreensão propriamente dita das transições e sim as interferências que cruzaram os artistas e levaram a tais gradações como, por exemplo, a intensificação dos avanços marítimos ou episódios políticos internos. A cada questionamento nos aproximávamos, portanto, do indivíduo e sua relação com seu meio natural e o impacto nas relações artísticas. Para este fim inicialmente caminhamos com autores, entre os quais: CAUQUELIN (2010) e COLI (2012), e a respeito de críticas ambientais, MATTOS (2010), BRÜGER (2006) e GUATARRI (2001). A partir da nitidez do objeto de estudo é que a abordagem metodológica do grupo toma uma maior proporção e interfere diretamente na dinâmica das pesquisas, o que ao ser compreendido justificará o constante retorno à utilização da História da Arte nas soluções propostas. 
Uma das principais características da abordagem do grupo é transitar entre as relações da arte com a natureza no passado e em suas relações contemporâneas, o que se consolida durante um levantamento a respeito da paisagem que nos revela que o termo surge primeiramente na pintura, e é posteriormente utilizado para nos referirmos à natureza (CASTRO 2006). Isso reforça o transito fluido entre arte e natureza, já que atualmente empregamos a palavra para falar do meio natural. A obra "Mato se reduzindo a carvão", representada abaixo pela Figura 3, de 1843, do artista Felix Taunay (1795-1881), filho de Nicolas-Antoine Taunay que veio ao Brasil na Missão Artística Francesa em 1816, nos reforça esta peculiar relação entre artista e natureza, pois através deste título de denúncia Felix Taunay demonstra sua preocupação com a transformação da paisagem natural, tal constatação nos leva a inúmeras hipóteses sobre a relação entre o artista e a natureza.

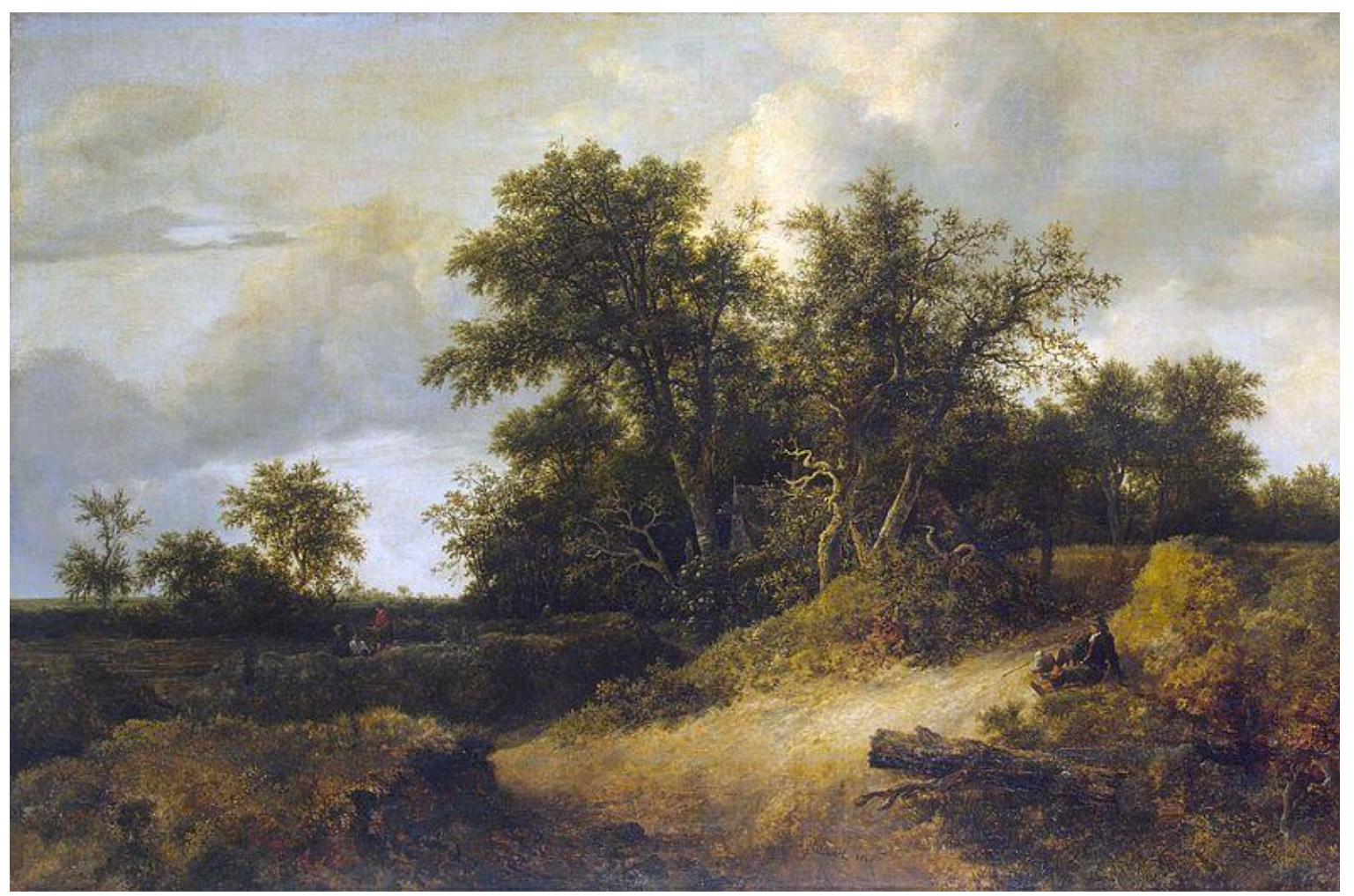

Figura 3. Mato se reduzindo a carvão (1843), Félix Émile Taunay. Fonte: https://goo.gl/8iAEjE

Os questionamentos a respeito da relação entre arte/natureza, artista/natureza culminam com a divulgação da temática da $32^{\mathrm{a}}$ Bienal de São Paulo, Incerteza Viva, que se propunha a tratar de pensamentos cosmológicos, inteligência ambiental e coletiva, assim como ecologias naturais e sistêmicas, refletindo sobre as atuais condições da vida e as estratégias oferecidas pela arte contemporânea para acolher ou habitar incertezas. Desse modo, considerando a Bienal de Arte de São Paulo como um importante parâmetro para mercado, circuito e pesquisa em Artes Visuais, a temática do nosso grupo se firmava, 
desafiando nossos estudos e possibilitando que avançássemos para reflexões a respeito da Arte Contemporânea e natureza.

A $32^{\circ}$ Bienal primeiramente nos remete à dois aspectos do grupo: a incerteza e a proximidade com as questões ambientais. Incerteza no sentido de que embora estivéssemos completamente envolvidos com o processo de pesquisa e conscientes, a caminhada cartográfica nos colocava em um dinamismo que poderia se confundir ou mesmo transparecer como incerto aos que não estivessem envolvidos no interior do processo. Portanto, qualquer tom de incerteza e instabilidade se dissipava mediante a confirmação que a Bienal nos proporcionara a respeito da trajetória do grupo. Mas no meio de tantos cruzamentos como se deu o papel da História da Arte nas reflexões do grupo?

Para melhor compreensão da metodologia do grupo e da relação com a História da Arte, é possível fazê-lo através do trabalho de Paulo Pasta, nascido na cidade de Ariranha, estado de São Paulo em 1959. Paulo é professor, pintor, desenhista e ilustrador, doutor em Artes Visuais pela Universidade de São Paulo. Primordialmente conhecido por suas telas, que segundo o próprio artista, falam quem ele é através das cores, um de seus principais temas. Ele transita entre abstração e figuração sem, no entanto, se condensar em qualquer uma delas, o faz através do trabalho complexo entre figura e fundo, trazendo uma ambiguidade para suas telas (PASTA, 2013). Pasta (2013) reconhece em seu trabalho a incerteza, e afirma ter uma obsessão em retomar suas origens. Embora seja reconhecido por seus trabalhos de figura e fundo, Pasta mantém uma produção de pintura de paisagens que em muito retomam a questão da origem, isso por que o artista não apenas se inspira nas paisagens de sua cidade de origem, mas também por que ao iniciar este trabalho ele sente a necessidade de estudar "seus antigos" e inicia pesquisas a respeito de Van Gogh, quando o faz ele descobre que Van Gogh havia feito o mesmo, estudando pintores de paisagem que o antecederam durante a produção de suas pinturas e que caíram no nosso esquecimento, mas que Pasta também se empenha em estudar. Ao iniciar seu trabalho em paisagem Paulo mantém o que ele denomina "seu outro trabalho", eles acontecem simultaneamente, um ajustando o outro até que o pintor possa compreender melhor como eles se conectam (PASTA, 2012). Por assim dizer, observase na movimentação de criação do pintor brasileiro, ao revisitar o passado da pintura de paisagem, a mesma postura de nosso grupo. E mesmo que isso não ocorra de maneira declarada, uma produção de Arte Contemporânea se utiliza, ainda que em silencio, de 
diversas referencias da História da Arte. Conhecê-la em sua linearidade propicia que esta seja reinventada ou ainda, que seja recurso para desenrolar de temáticas em novas linguagens, é como aquele que muito bem conhece as sutilezas da língua portuguesa podendo se utilizar da mesma para aprimorar sua expressividade sensível, não como uma necessidade, mas como um recurso bem-vindo.

\section{CONCLUSÃO}

Desse modo a História da Arte é para o nosso grupo uma malha de códigos que percorre os produtores de Arte Contemporânea e teóricos, e ainda que seja passado, se faz presente, e nos oferece base teórica e investigativa para a abordagem através da qual o grupo transita entre o passado da arte com a natureza e suas relações contemporâneas, assim a História da Arte tem para nós um papel fundamental. O avançar consciente de nossa metodologia nos possibilitara um trânsito característico do grupo que atua de modo a reproduzir o comportamento da Arte Contemporânea, o que se justifica pelo conceito de pré-individualidade, ou seja, o abandono de uma ordenação fixa da realidade, que nos leva ao espaço-tempo entre individual e coletivo (coletivo transindividual), gerando transformações no grupo, destaca-se neste contexto a metaestabilidade, ou seja, intervalo entre equilíbrio e desequilíbrio (ESCÓSSIA, 2007). Como metáfora para tal, a arte de Paulo Pasta, comparada pelo mesmo ao funambulismo (PASTA 2013), arte circense de caminhar sobre corda, que define sua relação complexa entre figura e fundo através da instabilidade da corda e a presença do equilíbrio. Sua pintura alude a ductilidade do presente, e seus gestos a passagens sem fim, portanto para Paulo e o grupo de estudos, a história é como potência de nossas circunstancias, alargando tempo-espaço para que se desfrute de maneira ilimitada e irrigada de ambos (NAVES, 1999), amalgamando o contemporâneo ao passado, sem ânsia pelo futuro.

\section{REFERÊNCIAS}

BRÜGER, Paula. O vôo da águia: reflexões sobre método, interdisciplinaridade e meio ambiente. Revista Educar, Curitiba, n. 27, p. 75-91, 2006.

CAUQUELIN, Anne. A invenção da paisagem. São Paulo: Ed. Martins Fontes, 2007. 152 págs.

CASTRO, L. Antes e Depois da Paisagem. APHA, @apha.Boletim n ${ }^{3}$ na Biblioteca Almeida Garret, 2006, p.19. Disponível em: <http://www.apha.pt/wpcontent/uploads/boletim3/LauraCastro.pdf>. Acesso em: agosto de2016. 
COLI, Jorge. O Brasil Retrato (2012). Palestra disponível em https://vimeo.com/70410198. Acesso em 10 de agosto de 2015. GUATTARI, Félix. As três ecologias. Campinas: Papirus, 2001.

ESCÓSSIA, L.; KATRUP, V.; PASSOS, E. (Org.). Pistas do Método da Cartografia: Pesquisa-intervenção e produção da subjetividade. Porto Alegre: Sulina, 2007.

KERN, M.L.B. História e Arte: invenções da paisagem. Em: XXVI Simpósio Nacional de História - ANPUH, 2011, São Paulo. XXVI Simpósio Nacional da ANPUH. São Paulo: ANPUH, 2011. p. 1-14.

NAVES, R. A espessura do presente. Galeria Millian, 1999. Disponível em: < https://goo.gl/7kXahw> Acesso em: 25 de outubro de 2016.

PASTA, P. Paulo Pasta. ArtDivisionBrasil, 2013. Disponível em: < https://goo.gl/5ws5dC> Acesso em: 25 de outubro de 2016.

PASTA, P. Fábula da Paisagem | Paulo Pasta | IFF. Pseudovídeo, 2015. Disponível em: < https://goo.gl/gm5t4O> Acesso em: 25 de outubro de 2016 